"Ramires from other eras and other spaces: brief comments on the appropriation of the nobiliary ethos in Portuguese America"

\title{
Os Ramires de outras eras em outros espaços: breves comentários sobre as formas de apropriação do ethos nobiliárquico na América portuguesa...
}

\section{Íris Kantor}

Professora do Departamento de História da FFLCH-USP

\section{Resumo:}

0 texto comenta o artigo de Nuno Gonçalo Monteiro, procurando mostrar a relevância de seu modelo de análise para a interpretação dos fenômenos societários na América portuguesa, principalmente no que diz respeito a três aspectos: a prática dos cerimoniais públicos, a afirmação do sentimento de fidalguia luso-americana e a elaboração da idéia de "utopia do poderoso império".

\begin{abstract}
:
The text comments on the article by Nuno Gonçalo Monteiro in an attempt to show the relevance of his model of analysis to the interpretation of events in the Portuguese-American society focusing on three main aspects: the adoption of the behavioral code of the nobility at formal public events, the reinforcement of the sense of identity among the Portuguese-American nobility and the creation of a project for a "powerful Portuguese-Brazilian empire".
\end{abstract}

\section{Palavras-chave}

sociedade, identidades, elites, América portuguesa/Brasil, Antigo Regime

\section{Keywords}

society, identities, elites, Portuguese America/Brazil, Ancien Régime 
Os Ramires doutras eras venciam com grandes lanças,

Este vence com um chicote,

Vede que estranhas mudanças!

É que os Ramires famosos,

Da passada geração,

Tinham a força nas armas

E este a tem no coração!

(Eça de Queiroz. A llustre Casa de Ramires, 1900)

Vitorino Magalhães Godinho. Estrutura da Antiga Sociedade Portuguesa, Lisboa, Arcádia, 1970; Mafalda Soares da Cunha e Nuno Gonçalo Monteiro (orgs). Optima Pars: Elites Ibero-americanas do Antigo Regime, Lisboa, ICS, 2005, p.191-242.

2

Mafalda Soares da Cunha e Nuno Gonçalo Monteiro (orgs). Optima Pars: Elites Ibero-americanas do Antigo Regime, Lisboa, ICS, 2005, passim.

Antonio Manuel Hespanha. "La Economia política de la Graça", in La gracia del derecho, Centro de Estudios Constitucionales, Madrid, 1993; Maria Fernanda de Olival. As Ordens Militares e o Estado Moderno: Honra, mercê e venalidade em Portugal (1641-1789). Lisboa, Estar, 2001; Nuno Monteiro. Elites e Poder: entre o antigo regime e o liberalismo, Lisboa, ICS, 2003.
0 artigo apresentado para discussão neste número do Fórum Almanach me fez lembrar o romance-novela A llustre Casa de Ramires. A irônica personagem de Eça de Queiroz, Gonçalo Mendes Ramires, ganha nova inteligibilidade na reconstrução que Nuno Monteiro fez do ethos nobiliárquico português. Neste meu breve comentário, desejo retomar os pressupostos de Monteiro, avaliando as apropriações dos códigos de conduta nobiliárquicos nas sociedades luso-americanas da época moderna.

Parece oportuno destacar que a análise sugerida por Nuno Monteiro alarga nossa percepção das urdiduras do moderno império português. Não cabe aqui recompor os argumentos do autor em sua inteireza, mas convém repensar nossa tradição de estudos sobre o período em questão à luz de sua chave interpretativa: a disciplina da Casa ou do ethos nobiliárquico. Arriscaria dizer que, se Nuno Gonçalo fosse antropólogo, seu trabalho poderia ser intitulado "As estruturas elementares da Casa ou do morgadio". Ao destramar as redes sociais que conformavam as estruturas imperiais, sua investigação abre novas perspectivas para a interpretação do passado colonial.

0 regime jurídico de vinculação de patrimônio (material e imaterial) e de transmissão das heranças, monopolizado pelas principais Casas da nobreza portuguesa, garantiu a estabilidade e coesão interna da alta nobreza, mas também selou sua dependência estrutural em relação ao monarca e ao Império, dada a importância fundamental das rendas provenientes do comércio e das alfândegas ultramarinas.

Em outro trabalho, Nuno Monteiro, Mafalda Soares da Cunha e Pedro Cardim nos ofereceram um ampla quadro das carreiras administrativas nos diferentes espaços geopolíticos do império português². Em diálogo com as obras de Antonio Manuel Hespanha e Fernanda Olival, Nuno Monteiro demonstrou que o regime de remuneração de mercês disciplinou a nobreza mais antiga do Reino, impulsionando, simultaneamente, à expansão das estruturas jurídico-administrativas nas conquistas ultramarinas ${ }^{3}$. 0 regime de remuneração de mercês consolidou-se com a lei mental (1436), entretanto, foi a partir do controle do Padroado (monopólio das comendas militares - 1551) que o impulso transformou-se em vetor de conquista, evangelização e colonização de outros e novos mundos.

0 historiador demonstra que o regime de mercês - ou a recompensa do rei por serviços prestados em benefício da Coroa - emulou a constituição de uma elite fechada no topo da pirâmide social e, simultaneamente, alargou a legitimidade da realeza entre os súditos ultramarinos através dos dispositivos de concessão de privilégios, ofícios públicos, sesmarias, hábitos das ordens militares, familiaturas do santo oficio, etc. De modo que 
Refiro-me aqui às conclusões aventadas pelo importante trabalho publicado por João Fragoso, Maria Fernanda Bicalho e Maria de Fátima Gouvêa, 0 Antigo Regime nos trópicos: a dinâmica imperial portuguesa, Rio de Janeiro Civilização Brasileira, 2001

Sobre essas limitações, veja-se o artigo de José Augusto França. Burguesia pombalina, nobreza mariana, fidalguia liberal, in Pombal Revisitado Lisboa, Estampa, 1984, p. 19-33, e também o de Jorge Miguel Pedreira. Brasil, fronteiras de Portugal, negócio, emigração e mobilidade social, in Mafalda Soares da Cunha (org.), Do Brasil à Metrópole: efeitos sociais (século XVIIXVIII), Évora, 2001, p. 47-72.

Fernando Antonio Novais. A Evolução da sociedade brasileira: alguns aspectos do processo histórico da formação social no Brasil, Anais do Museu Paulista, volume 29, 1979. p.51-63; István Jancso. Independência: história e historiografia, São Paulo, Hucitec, 2005.

Julita Scarano. Devoção e Escravidão: A irmandade de Nossa Senhora do Rosário dos Pretos no distrito Diamantino no século XVIII, São Paulo, Companhia Editora Nacional, 1978; Caio Boschi. Os leigos e o poder. São Paulo: Ática, 1986; Marcos M. Aguar.Vila Rica dos confrades: sociabilidade confrarial entre negros e mulatos no século XVIII, São Paulo, FFLCH-USP, 1993. (tese de doutorado); Antonia Quintão. As irmandades de pretos e pardos em Pernambuco e no Rio de Janeiro na época de D. José I", in Beatriz Nizza da Silva. Brasil: colonização e escravidão, Rio de Janeiro, Nova Fronteira,

8

Maria Fernanda de Olival. As Ordens Militares e o Estado Moderno...Op.cit

Junia Ferreira Furtado. Homens de negócio: a interiorização da metrópole e o comércio nas minas setecentistas. São Paulo: Hucitec, 1999; João Fragoso, M. Fernanda Bicalho, M. de Fátima Gouvêa (Orgs.). Prefácio. 0 Antigo Regime nos trópicos: a dinâmica imperial portuguesa. Rio de Janeiro: Civilização Brasileira, 2001. a rigidez no topo e a fluidez na base social iam promovendo a contínua segmentação da nobreza, isto é, a hierarquização representada por um gradiente que ia da Grandeza à "nobreza da terra". Ao fim e ao cabo, a Grande nobreza do reino se manteve intacta, impermeável aos grupos sociais ascendentes, embora cada vez mais dependente da benemerência régia. Esse modelo perpetuou-se - apesar das investidas pombalinas - até a revolução liberal em 1832.

Penso que as análises de Nuno Monteiro relativizam as visões correntes sobre as possibilidades de ascensão das elites oriundas do ultramar aos centros do poder político metropolitano ${ }^{4}$. Embora tenha havido espaços de partilha e de arregimentação dos luso-brasileiros na composição dos diferentes órgãos da administração central do Império - sobretudo a partir da segunda metade do século XVIII - o quadro traçado supõe condicionantes e limitações à reprodução social dessas elites no espaço político reinol 5 .

Portanto, aos historiadores do moderno império português coloca-se o problema de compreender os modos de reprodução social do ethos nobiliárquico nas diferentes partes do Império. De que maneira os princípios ordenadores da vida social - tais como: condição de nascimento, pureza de sangue, limpeza de mãos, cor da pele - atuavam na conformação das hierarquias nos territórios onde o escravismo articulava todas as relações sociais? 6

Enfim, quero apenas chamar a atenção às especificidades locais e aos arranjos complementares entre as estruturas societárias no Reino e nas Colônias, uma vez que os mesmos principios ordenadores da vida social funcionavam de maneira diversa e heterogênea nos diferentes espaços geopolíticos. 0 regime de remuneração de mercês operava através de uma lógica dual e complementar: reforçava o centro político metropolitano, ao mesmo tempo que expandia a fidalguia de baixa extração nas colônias.

Os resultados das pesquisas do grupo liderado por Nuno Monteiro evidenciam que as mercês não constituíram dispositivos de ascensão social à alta esfera de decisão política da Coroa, embora elas tenham representado um poderoso mecanismo de transmissão dos códigos de conduta estamentais nas sociedades escravistas coloniais. Assim, compreende-se que tais códigos fossem apropriados por diferentes grupos sociais - incluindo os segmentos escravos e libertos - a exemplo de certos privilégios outorgados às irmandades de negros forros ${ }^{7}$. Enfim, como mostrou Fernanda Olival, as mercês captavam lealdades ao criar um horizonte de expectativas de recompensa pelos serviços prestados à Coroa, embora não constituíssem vetores de mudança social. Isto porque os privilégios eram vitalícios, mas não hereditários, cabendo aos reis, a cada novo reinado, confirmar a transmissão das mercês às gerações seguintes ${ }^{8}$.

Nos últimos anos, a historiografia brasileira tem explorado o impacto do regime de remuneração de mercês ou da economia do privilégio no processo de estruturação das elites coloniais ${ }^{9}$. De fato, a configuração escravista da sociedade colonial produziu uma gama de situações bastante peculiares, como se pode observar nas festividades públicas, em que as hierarquias e os signos de distinção social adquiriam novos e inusitados significados diante da diversidade étnica, cultural e religiosa dos habitantes da América. Embora houvesse dispensa de gentilidade (ascendência indígena) e de defeitos mecânicos (trabalho manual), os princípios de ordenação baseados na condição de nascimento, cor da pele e pureza de sangue 


\section{1}

Silvia Hunold Lara. Fragmentos Setecentistas: escravidão, cultura e poder na América portuguesa, Livre docência, UNICAMP, 2004.

12

Representação da Mesa do Bem Comum contra a pragmática de 1749. Cf. Luis Fernando de Carvalho Dias. Luxo e pragmática no pensamento econômico do século XVIII, Coimbra, Faculdade de Direito, Boletim de Ciências Econômicas, 1958, p.113.

13

Idem, ibidem. representavam dispositivos permanentes de desclassificação social ${ }^{10}$. De tal modo que a presença de mestiços e negros forros em posições de visibilidade nos cortejos e ritos públicos contrastava com a rigidez do código estamental reinol.

A dificuldade de aplicação das leis anti-suntuárias decretadas em maio de 1749 (revogadas em setembro do mesmo ano) evidencia as especificidades e contradições próprias do universo escravista colonial111. A pragmática proibia que negros e forros usassem tecidos finos, bordados e dourados e trouxessem espada ou espadim à cinta nas festividades públicas. Ao mesmo tempo, o afidalgamento dos mulatos quebrava a rigidez das regras estamentais. Contudo, os negociantes de Lisboa advertiram que tal legislação não mais deveria ser aplicada nas conquistas da América, pois estava colocando em risco os interesses comerciais e as lealdades dos vassalos ultramarinos. A petição dos negociantes sugere os limites do pacto colonial:

"Até agora senhor, vinham as frotas carregadas dos gêneros da América, porque as fazendas que iam do Reino, lá tinham consumo: vinham os cabedais do Brasil para Portugal, porque de Portugal iam as fazendas, que no Brasil se transmudavam. Agora porém, que a nova pragmática proibe aos negros e mulatos, usarem das fazendas que iam do reino, cessa o meio de transmutação, e ficam na América os cabedais, que em todo o tempo sempre o zelo dos conselheiros lembrou, deviam extrairse para o Reino, para que a demasiada opulência daqueles vassalos os não faça estranhos à obediência necessária"12.

Os negociantes alertavam também para as conseqüências políticas das restrições impostas aos vassalos mulatos, uma vez que estes ocupavam os cargos das vereanças: "do mesmo modo na república da América são os mulatos os que constituem o maior corpo e parece que esta inferior condição com que nasceram, os não deve privar do crédito, e estimação de que se fazem credores na república donde eles constituem maior corpo"13.

No que toca ao papel das festividades públicas na reiteração dos códigos estamentais do reino, verifica-se um duplo movimento - a demarcação de fronteiras sociais é acompanhada da inversão dos significados originários. Enfim, a incorporação das populações africanas e ameríndias implicou a elaboração de novos códigos de conduta na vida pública e doméstica. Pode-se falar num duplo papel cumprido pelas festividades públicas. 0 primeiro, voltado ao público externo, de canal para a publicização das elites nativas através da difusão dos panegíricos circuitos do Paço Real. E um outro, voltado às demandas locais, de instrumento para a acomodação das tensões sociais internas e manutenção de algum grau de negociação entre os diferentes grupos sociais. Nesse sentido, as práticas de ostentação do luxo adquiriam conotação política, não apenas por reforçar as estruturas paternalistas de dominação, como também por funcionar como elemento de contrafação das hierarquias oficiais.

No cotidiano, o vestuário de luxo e a exibição de insígnias de prestígio estavam intrinsecamente relacionados ao exercício do mando, a aparência e visibilidade pública eram expressão do poder político e demarcavam fronteiras sociais e clivagens étnicas. 0 porte da bandeira de ofício, do estandarte real do senado, das varas pelos juizes, do pálio pelos camaristas nas ocasiões solenes era investido de significado ritual e sua vulgarização era politicamente indesejável e socialmente perigosa na urbe colonial.

Freqüentemente a banalização das insignias durante os ritos solenes suscitava a intervenção do poder real para arbitrar os conflitos entre as 
14

Ordem régia (13/02/1727), Arquivo Público Mineiro, CMOP, cod.7

\section{5}

Diogo Pereira Ribeiro de Vasconcellos. Breve descrição geográfica da Capitania de Minas Gerais, Belo Horizonte, Fundação João Pinheiro, 1994, p. 96

16

Instrução e Norma, RAPM, ano IV, 1899, p. 727735 .

\section{7}

Laura de Mello e Souza. "Os ricos, os pobres e as revoltas nas Minas do século XVIII". Análise e Conjuntura. Belo Horizonte, Fundação João Pinheiro, no 2/3, maio/dez. 1989, vol. 4
18

Gonzaga, Tomás A. Cartas Chilenas, São Paulo, Cia das Letras, 1995 p. 122 esferas de poder local, tanto civis como eclesiásticas. Em 1727, o governador de Minas D. Lourenço de Almeida recebeu uma carta régia que fixava o protocolo de precedência nos atos públicos. 0 lado direito do governador era reservado aos ministros civis e o esquerdo, aos militares. Em princípio, devia-se guardar a ordem praticada nas igrejas ${ }^{14}$. Os párocos deveriam receber os vereadores da Câmara e despedir-se destes à porta da igreja, com repique de sinos. Além disso, os vereadores e governadores tinham direito de ser incensados durante a missa ${ }^{15}$. Nas instruções de Gomes Freire de Andrade ao governo da Minas Gerais, as observações em relação à importância dos ritos de reverência são bem claras: os eclesiásticos tinham a precedência nas audiências e tanto a Câmara como o Cabido deveriam ser acompanhados até a porta ${ }^{16}$. 0 exercício do Padroado Real nas conquistas ultramarinas criava tensões entre as esferas de poder civil e eclesiástico, as quais eram distintas daquelas conhecidas no Reino.

As "descortesias públicas" durante as cerimônias geravam constantes representações ao poder real. Os vereadores reclamavam da falta de ductos nas missas, os eclesiásticos acusavam os governadores de tomar lugar diante do pálio, reclamava-se ao rei da desatenção dos padres durante a missa. Em Minas Gerais a polarização entre os poderes eclesiásticos e civis era ainda maior, em decorrência das proibições de estabelecimento das ordens religiosas na Capitania.

A necessidade de prescrever o lugar dos indivíduos e grupos nas cerimônias e ocasiões públicas fazia parte do processo de sedimentação hierárquica, calcado nos critérios de riqueza, cor e honra ${ }^{17}$. Nas Cartas chilenas, o autor critica a falta de rigor na prática dos códigos estamentais, acusando a soberba do governador, que nos dias de festa exigia uma deferência sem medida durante a missa:

Chega enfim o dia suspirado,

O dia do festejo: todos correm

Com rostos de alegria ao santo Templo;

Celebra o velho Bispo a grande Missa;

Porém o sábio chefe não the assiste

Debaixo do espaldar, ao lado esquerdo:

Para a tribuna sobe e ali se assenta.

Uns dizem, Doroteu, fugiu prudente,

Por não ver assentados os Padrecos

Na Capela maior acima dele.

Os outros Sabichões, que a causa indagam,

Discorrem que o senado Ihe devia

Erguer, no Presbitério, dossel branco,

Em honra dele ser Lugar Tenente.

Mas eu com estes votos não concordo,

E julgo afoito, que a razão foi esta:

Porque estando patente, e tendo posto

O seu chapéu em cima da cadeira,

Pudera duvidar-se, se devia

O Bispo ter a Mitra na Cabeça ${ }^{18}$

Penso que os estudos sobre ritualidade pública nos ajudam a desvendar o processo de apropriação cultural dos códigos de conduta de antigo regime em sociedades escravistas. No artigo em discussão, Nuno Monteiro nos apresenta uma série de pistas importantes para repensar 
19

Evaldo Cabral de Melo. Rubro Veio: 0 imaginário da Restauração pernambucana, Rio de Janeiro, Editora Nova Fronteira, 1986. p. 109.

20

BNL. Fundo Geral. Mss. Cód. 630, fl.8 e 9

21

Íris Kantor. Esquecidos e Renascidos: historiografia acadêmica lusoamericana (1724-59), São Paulo, Hucitec, 2004. (parte II)

22

István Jancsó. Independência, independências. Independência: História e historiografia, São Paulo, Hucitec, 2005., o enraizamento do ethos nobiliárquico em colônias. Sob esse aspecto, parece relevante recuperar o vocabulário social e as classificações que as elites coloniais se auto-atribuiam. Tome-se, por exemplo, o programa de elaboração da História Universal da América Portuguesa, proposto pela Academia Brasílica dos Renascidos em 1759. As elites letradas empenharam-se na construção de uma memória da fidalguia luso-americana que Ihes permitisse não somente reivindicar honras e mercês, como também demarcar uma fronteira identitária através da ficcionalização do tempo e do parentesco. Ao enaltecer sua ancestralidade indigena, os eruditos transformavam o sangue caboclo em marca de distinção perante os demais grupos adventícios ou de menor sedimentação social ${ }^{19}$. De modo que a desqualificação e o rebaixamento intelectual e moral do indigena contemporâneo (objeto e sujeito da legislação pombalina antidiscriminatória) articulavam-se de maneira contraditória e complementar com a retórica de heroicização do ancestral indígena, considerado como o herói fundador das principais linhagens da nobreza da terra.

Nesse contexto, a idealização da ancestralidade indígena suscitava a construção de um "outro" índio, muito diverso daquele que estava sendo objeto da legislação pombalina. A distância entre o ancestral indigena e o indio contemporâneo era patente nos joco-sérios recitados por Silvestre Oliveira Serpa no dia da inauguração da Academia dos Renascidos: "Pois querem da nobreza ser a gema/ enfim para o aparelho/ já cada um comprou o seu espelho"20. 0 indianismo erudito e o indigenismo pombalino constituiam duas faces da mesma moeda nesta conjuntura especifica de redefinição das fronteiras luso-espanholas no continente americano (17501777)21.

Embora a camada dominante tendesse a ver a si própria como uma camada senhorial, incorporando os valores da nobreza tradicional, as condições coloniais davam lugar a novas tópicas e arranjos de classificação e desclassificação social. 0 processo de colonização engendrou diferentes sociedades, segundo a época da conquista e as formas de exploração da terra. Com efeito, os mitos de origem da nobreza da terra justificavam os direitos à posse imemorial da terra. Ao construírem uma visão do seu passado e do processo de colonização, as elites luso-americanas tinham em mente a obtenção de mercês e a consagração de suas famílias. Foi provavelmente a frustração desse projeto - proibido por Pombal - que transformou o emergente sentimento de linhagem em um ressentimento americanista.

Enfim, a camada dominante incorporava os valores da alta nobreza portuguesa, a despeito do fato de que o seu teto de ascensão social e enobrecimento ser limitado pelos padrões vigentes no Reino. Por outro lado, conforme observa István Jancsó, as condições de vigência do Antigo Regime em colônias pressupunham, em boa medida, a fixação de uma dada memória ou tradição que conferisse precedência aos primeiros clãs povoadores ${ }^{22}$.

Um último desdobramento que o artigo em tela nos sugere diz respeito ao problema da circulação social das elites americanas nas diferentes instâncias da administração central e imperial lusitana. Através de uma minuciosa e consistente análise das carreiras administrativas no Império, Mafalda Soares da Cunha e Nuno Monteiro verificaram o acentuado processo de elitização ou aristocratização dos governadores coloniais no final do século dezoito. Vemos aqui um movimento inverso ao 
23

Stuart Scharwtz. Burocracia e Sociedade, São Paulo, Perspectiva, 1979.

24

José Antônio Gonsalves de Mello. Estudos pernambucanos. 2. ed. Recife: Fundarpe, 1986, p.195. Sobre as fraudes genealógicas na familia de Pombal veja-se Camilo Castelo Branco. Perfil do Marquês de Pombal, Porto Editora, 1971 (7 ed.), p. 59 e seguintes... que poderíamos chamar de crioulização ou abrasileiramento da burocracia colonial (no que toca à gestão das capitanias). Resta-nos, portanto, inquirir sobre os demais espaços da administração judiciária e eclesiástica, onde a circulação das elites luso-americanas parece ter sido bem mais fluente e aberta aos nascidos no Brasil23. Neste diapasão, cabe ainda indagar o peso do pedigree americano nas práticas políticas do Reino, conforme apontou Nuno Monteiro ao se referir aos impedimentos colocados ao irmão de D. Rodrigo de Sousa Coutinho. 0 próprio pai de Pombal teria intentado elidir tais máculas de origem na árvore genealógica familiar 24 .

Caberia ainda avaliar de que maneira o ethos nobiliárquico foi assimilado pelas elites americanas no interior do projeto reformista ilustrado. Com efeito, indivíduos naturais da América podiam ascender aos postos importantes da administração régia no final do Antigo Regime, mas não chegariam nunca a receber as nobilitações superiores. Podiam circular entre as diferentes partes do império, mas não almejavam romper o círculo de giz que cercava a Grande Nobreza do Reino.

As análises clássicas sobre a geração de 1790 - realizadas por Maria Odila Leite da Silva Dias, Fernando Novais e Kenneth Maxwell - demonstraram a importância do ideário reformista na geração que participou do processo de emancipação política do império brasileiro. Após a leitura do artigo de Nuno Monteiro, ficou-me a impressão de que a "utopia do poderoso império luso-brasileiro" (que se realizaria com a transferência da Corte para a América, proposta por D. Rodrigo de Sousa Coutinho) era, ao fim e ao cabo, o único horizonte possivel de ascensão dos grupos marginalizados pela rigidez das regras do "modelo reprodutivo vincular" que estruturava a sociedade e o Estado português. Somente na América as elites luso-americanas poderiam vislumbrar um futuro mais promissor, já que a sua ascensão social e a conseqüente partilha do poder no Reino estavam bloqueadas. 